\title{
DIE LEWENSWYSE VAN DIE SUID. AFRIKAANSE JEUG VANAF 1652 TOT VOOR DIE VOORTREKKERTYDPERK
}

Lt A.M. le Roux*

\begin{abstract}
The life style of the South African Youth from the year 1652 up to the Voortrekker era is depicted in this article. Conditions during these pioneering days are sketched as well as problems on the Eastern frontier, the role of the 1820 Setlers and the enormous problems presented by the Xhosas.
\end{abstract}

\begin{abstract}
Inleiding
Die eerste Blanke kinders aan die Kaap was die wat saam met Jan van Riebeeck in 1652 in die Kaap die Goeie Hoop aangekom het. Die Hollandse Oos Indiese Kompanjie (HOIK) het besluit om 'n verversingspos aan die Kaap te stig om vars voorrade aan sy skepe te voorsien. ' $n$ Afvaardiging bestaande uit soldate en werkslui onder kommandeur Jan van Riebeeck is gestuur om sodanige vesting te gaan oprig. Die lede van die ekspedisie het die tog met drie skepe, wat met toerusting en voorrade gelaai was, aangepak. Van die lede het hulle families saamgeneem; so is Van Riebeeck deur sy vrou en seuntjie vergesel. Die sieketrooster Willem Barentsen Wijlant, die dokter De Jager en Hendrik Boom, die tuinier het hulle vrouens en kinders ook saamgeneem.
\end{abstract}

Die vermoeiende seereis vanaf Holland na die Kaap het sowat vier maande geduur. Dit was veral uitputtend vir die kinders gewees. Die beknopte beweegruimte op die skepe het rondhardloop en speel heeltemal onmoontlik gemaak. Bo en behalwe die gebrek aan spasie, was daar die onophoudelike gebrek aan voedsel en drinkwater. Rantsoene het bestaan uit soutvleis, gepekelde vis, droë bone en -ertjies, goor botter en oorryp kaas. Al die voedsel is in soutwater gekook en het tot gevolg gehad dat almal altyd dors was. 'n Gebrek aan higïene, vars lug en privaatheid het bygedra tot die passasiers se misnoeë. Boonop was daar altyd die bedekte vrees vir storms, vuur, aanvalle deur seerowers en epidemies. Die uitbreek van 'n aansteeklike koors het ook verskeie kinderlewens bedreig en het die lewe van een van Hendrik Boom se kinders geeïs.

\section{Kinders van die sewentiende eeu}

Sover vasgestel kan word, was daar agt seuns en een dogter onder diegene wat uiteindelik in
Tafelbaai aangekom het. Van Riebeeck se geselskap het dadelik aan die werk gespring. Die kinders wat oud genoeg was het met die kleiner takies gehelp. Aanvanklik het die kinders die lewe geniet, totdat die nat en koue weer op die setlaars toegesak het. Dit het tot gevolg gehad dat die Hottentotte nie meer vee vir ruilhandel gebring het nie, dus was die setlaars sonder vars vleis. Skepe wat die vesting van voorrade moes voorsien het nie opgedaag nie en die see was te onstuimig om hulle eie vis te vang.

Eers teen die begin van die somer kon hulle weer vleis en melk kry. Aanvanklik was dit so droog dat niks wou groei nie en toe die eerste winterreëns val, het alles verspoel. Hulle was dus afhanklik van wilde groentesoorte en vleis, wat baie skaars was omdat die lomp gewere nie van veel nut vir jag was nie. Boonop was die Hottentotte vol nukke en grille en onbetroubaar en kon Van Riebeeck-hulle nie op ruilhandel staatmaak vir vleis nie.

Die hongersnood wat twee jaar na Van Riebeeck se koms aan die Kaap gedreig het, kon grootliks toegeskryf word aan die Blanke afhanklikheid van Hottentot-willekeur'.

Vanweë die gevare het Van Riebeeck en sy mense dadelik ' $n$ Fort begin bou vir beskerming. Voordat die bouwerk egter voltooi was, het die reën en koue op hulle toegesak. Baie mense het siek geword omdat hulle net houthutte vir beskerming gehad het. In Junie was slegs 60 van die 116 arbeiders op die been en voor die einde van Augustus het daar reeds 18 mense gesterf ${ }^{2}$. Op 3 Augustus 1652 het die mense die Fort betrek - hulle was nou beskerm maar die wildediere het op die vee toegeslaan.

Bo en behalwe die gevaar van die wilde diere het die teenwoordigheid van die Hottentotte al 
hoe meer gevaar begin inhou. Hulle het gou alle ontsag vir die Blankes verloor en was later so parmantig dat hulle setlaars wat alleen en ongewapen was, van hulle besittings beroof het. Sommiges was so astrant dat hulle die koperknope van die kinders se baadjies afgeruk het ${ }^{3}$. In 1653 het Harry die Hottentot 40 beeste van die Kompanjie gesteel, nadat hulle 'n Blankeseun, wat saam met die soldate vee opgepas het, vermoor het - die eerste slagoffer van inboorling misdadig- en onbetroubaarheid ${ }^{4}$.

In 1659 het die Hottentotte die setlaars openlik aangeval en hulle vee weggevoer, alle hoop vir 'n vreedsame bestaan was daarmee heen. Boere is opgeroep om die soldate by te staan terwyl ander na die fort gevlug het uit vrees dat hulle huise afgebrand sou word. $\mathrm{Na}$ ' $\mathrm{n}$ bittere stryd is die Hottentotte verslaan en was hulle verplig om die feit te aanvaar dat die boere die grond langs die Liesbeeckrivier bewoon het. Die Blankes het nou weer die drade van hulle boerdery bymekaar gehark en mens wonder of die kinders die angswekkende ondervindings van geweld en bloedvergieting van die vorige paar maande kon vergeet het.

\section{Kinders van die agtiende eeu}

Kinders wat in die wilde binneland van die Kaap grootgeword het, het dit baie moeiliker gehad as die wat in die distrik van Tafelbaai opgegroei het. Hulle ouers was veeboere en het ' $n$ nomadiese bestaan gevoer vanweë hulle onophoudelike soeke na weiding. Kinders het onder moeilike omstandighede grootgeword en luukshede was ' $n$ ongekende ding. In hierdie gesinne is egter die fondament gelê vir die samelewing vandag. Die kern in die gesinne was hulle liefde vir mekaar. Ouers sowel as kinders was min tuis. Hulle het slegs tuis geëet en geslaap en dikwels was daar vir die kinders geen speelplek in of om die huis $n^{5}{ }^{5}$. Kinders het ook meestal kaalvoet geloop, selfs in die winter. Hulle het ook geen speelgoed gehad nie en moes dit wat hulle wou hê, self maak soos bv klei-osse en lappoppe.

Hulle het ook gou gewoond geraak aan die konstante gevoel van vrees vanweë die bedreiging wat die wildediere vir hulle ouers se vee ingehou het. Boonop het die Boesmans altyd oral gereed gelê om vee te buit as die kans opgeduik het ${ }^{6}$.

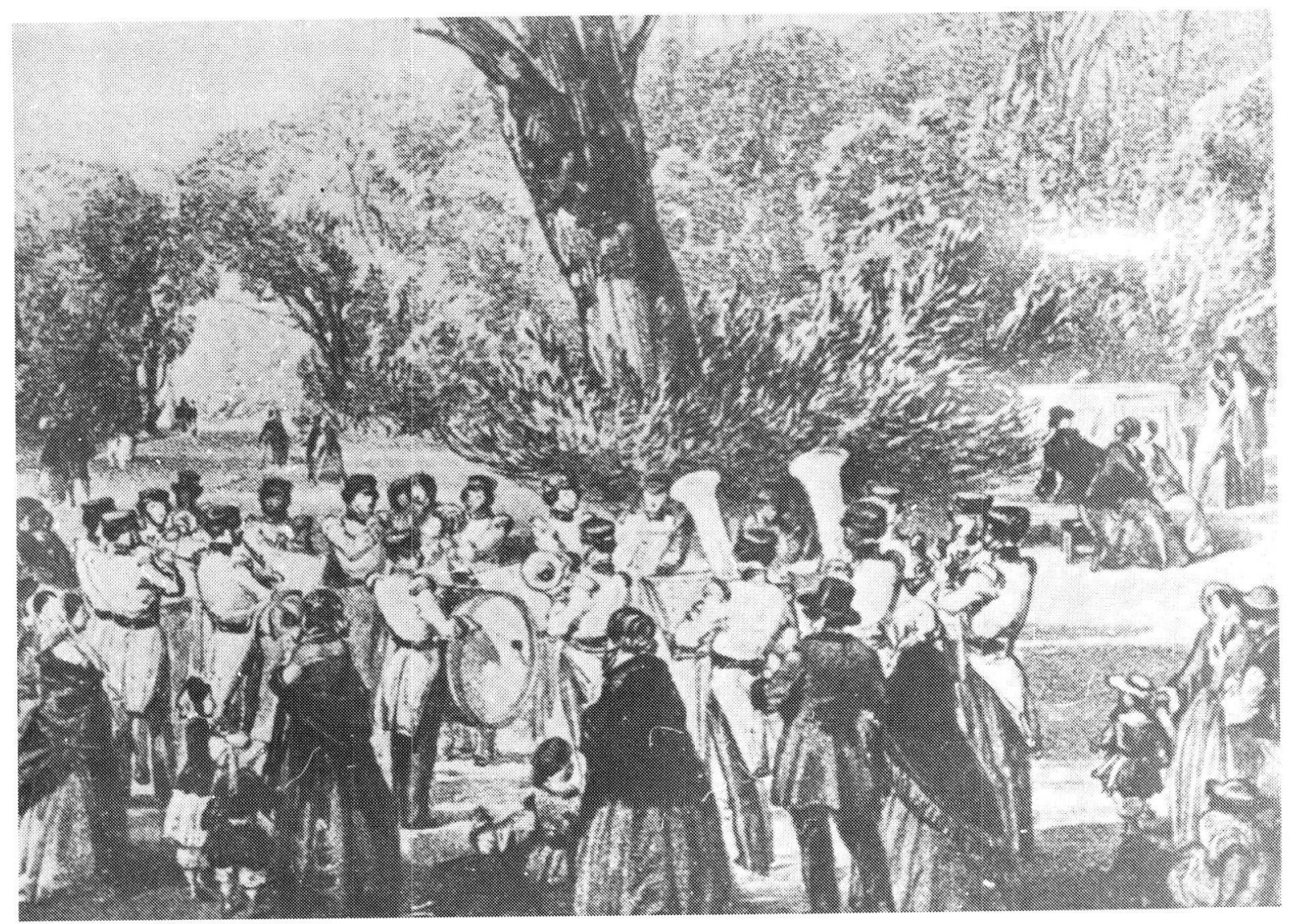

Kinders van die 1850's het baie tyd saam met hulle ouers in die Kaapse tuine deurgebring. 
'n Seun se lewe was soortgelyk aan die van 'n soldaat want dit het bestaan uit lang periodes van rustigheid, wat afgewissel is met uitbarstings van geweld of tydperke van uiterste gevaar, want die gevare van die wildernis het baie nare ondervindinge meegebring, waarin die hele familie soms betrokke was ${ }^{7}$. So het die reisiger Thunberg die volgende tragedie beskryf. 'n Veeboer se vrou wou een aand 'n leeu by die kraal verskrik. Die gedierte het haar aangeval en ten aanskoue van haar kinders verskeur. Die huis het net een deur gehad wat in die rigting van die kraal gewys het en die kinders het 'n gat deur die moddervloer onderdeur die muur gegrawe. Hulle het hulp gaan soek by die bure wat etlike kilometers daarvandaan gewoon het.

In die 17 e en 18 e eeu is seuns aan die kaap op die ouderdom van 15 jaar deur die wet verplig om by die burgermag aan te sluit; wat saamgestel is ter verdediging van die land. Die seuns is deur dieselfde militêre-opleiding as die mans. Dit het beteken dat hulle skiet- en perdrystandaard baie hoog vir hulle ouderdomme moes wees. ' $n$ Troepeskouing is jaarliks gehou waar daar onder andere gekyk is na die paraatheid van die berede- en voetsoldate. Mans en seuns wat nie opgedaag het nie, is beboet.

Die boere se berede eenhede het as kommando's bekendgestaan en elkeen het ' $n$ bepaalde plek van byeenkoms gehad waarheen hulle dmv geweervuur, hysing van 'n vlag of die aanblaas van 'n seinvuur geroep kon word ${ }^{8}$.

\section{Probleme op die Oosgrens}

Die verskil in leefwyse en kultuur van die Blankes en die Swartes was 'n groot rede vir die probleme op die Oosgrens. Die verskillende swartstamme het onafhanklik onder verskillende leiers gestaan. Onrus en interne stryd het dikwels onder hierdie groepe bestaan en dit het bygedra tot die botsings wat gevolg het met die aankoms van die Blankes by die oosgrens van Kaapland.

Die blankebevolking was yl verspreid, dit het die selfverdedigingstelsel besonder bemoeilik en die huisgesinne des te meer blootgestel aan strooptogte en barbare. Die militêre stelsel was eenvoudig, maar mettertyd het die boere ' $n$ komandostelsel op die been gebring. Die stelsel was nie voldoende nie want sodra die swartes met die vee oor die grens was, was die stryd verlore. Die organisasie van 'n kommando was eenvoudig. Elke distrik is in etlike wyke opge- deel wat onder bevel van 'n veldkornet was. Hierdie veldkornet moes aan die betrokke landdros verslag doen. Elke distrik het ook oor 'n paar veldkommandante beskik wat die kommunikasie in operasies moes lei. Beide die veldkommandante en veldkornette se dienste was vrywillig. Boere het ook nie 'n keuse gehad nie, as hulle opgeroep is, moes hulle gaan. Boonop het hulle geen soldy ontvang nie. 'n Boer en sy seun kon ook vir 'n onbepaalde tydperk op kommando wees en dan was sy huis en besittings oorgelaat aan die lot van die swartbendes, rondloper Hottentotte en moedswillige slawe ${ }^{9}$.

Tydens sy besoek aan die Oosgrens in 1778 , het goewerneur Van Plettenberg 'n grenslyn tussen die Blankes en die Xhosas ingestel om botsings vanweë die deurmekaarwonery te voorkom. Die Xhosas het hulle nie daaraan gesteur nie en die boere het met 'n kommando op bevel van die regering, die Xhosas oor die Visrivier gedryf.

In 1779 het die Eerste Grensoorlog uitgebreek. Die Xhosas het 'n klomp Hottentotte vermoor en vee van die Blankes gesteel. 'n Reeks uitgebreide skermutselings het gevolg, waarin die Xhosas - wat in regimente geveg het en met assegaaie en beesvel-skilde bewapen was die wêreld vir die berede koloniste met hulle lomp muskette moeilik gemaak het. So het die een oorlog na die ander gevolg net ter wille van veebesit ${ }^{10}$.

In 1810 was daar in die omgewing van $\mathrm{Ba}$ viaanskloof tussen 40 en 50 weerbare manne dit agv die aanhoudende blootstellings aan die swart invalle. Elke familie was dus verantwoordelik vir sy eie beveiliging teen die hordes ${ }^{11}$. Teen die einde van 1810 was die invalle aan die oosgrens stiller. Dit kan toegeskryf word aan die kort somernagte omdat vee nie betyds oor die grense gedryf kon word voordat die dag breek nie.

Januarie 1811 word gekenmerk aan die afwesigheid van alle militêre-operasies vanweë die rustiger toestande wat geheers het. Vanaf April het ' $n$ brutale gees hom onder sommige van die rowerbendes geopenbaar. Op 8 Mei 1811 word berig ontvang van die moord op die twee Slabber broers. Pieter en Nicolaas was op die trekpad toe hulle deur ' $n$ bende swartes aangeval is. Die twee broers is vermoor en al hulle besittings is afgeneem. Die vrou en vyf kinders is met leë hande agtergelaat en moes gaan hulp soek $^{12}$. 
Die daaropvolgende dag is berig ontvang van die moord op Jan Davel en die twintigjarige Jacob de Winter. Laasgenoemde het ' $n$ trop vee opgepas waartydens hy deur swartes verras en vermoor is ${ }^{13}$

\section{Die 1820 Setlaarkinders}

Die 1820 Setlaars het min of meer dieselfde ontberings gehad as die Hollanders en Hugenote wat in die 17 e eeu na Suid-Afrika gereis het, want die gevare op see was steeds groot. Hulle seereis in die klein oorbelaaide skepies het drie maande geduur en in daardie tyd is 18 kinders dood.

Die Setlaars is in die Suurveld gevestig om as grensbuffer te dien ${ }^{14}$. Weinig van die Setlaars het enige kennis van boerdery gehad en die boerderymetodes in Engeland het hemelsbreed verskil van die in die Suurveld. Met die koringoeste het dit in die begin glad nie goed gegaan nie. Die eerste oes is deur roes verniel en daarna het buitengewone storms en verspoelings, nie alleen die oes nie, maar ook die huisies van die Setlaars verwoes. Die land is deur oorstromings geteister en die Setlaars was diep in die skuld by die regering. Hulle het met reg gekla dat die plase te klein was. Aan die wat op die plase gebly het, is meer grond gegee ${ }^{15}$.

Die Setlaars se georganiseerde lewenstyl is binne een jaar na die aankoms van die Xhosaplunderaars, wat die grense oorgesteek en die Blankeboere gemolesteer het, versteur ${ }^{16}$. 'n Gespanne atmosfeer het veroorsaak dat niemand kon tuis voel nie. Xhosas het snags mbv brandende assegaaie die plaashuise aan die brand gesteek.

Die 15 jarige Benjamin Anderson was die eerste slagoffer van die Xhosas se brutale moorde. Nadat hy doodgesteek is, is meer as die helfte van die veekudde oor die grens gevoer. Dit was die begin van ' $n$ reeks moorde wat 'n sewe en twaalfjarige veewagtertjie ingesluit het. Sommige kinders het gelukkiger daarvan afgekom en is net gedreig voordat hulle vee gesteel is.

Die 1828 gevegte op die grens was die voorloper van die volskaalse Xhosa-oorlog wat in Desember 1834 uitgebreek het. Met die koms van die sendeling dr John Philip in 1830 het hy met sy veldtog teen die kommando's begin. Hy het beweer dat die kommando's roofekspedisies was wat onskuldige swartes in behoeftige rondlopers verander het ${ }^{17}$. In 1833 het die minister in Engeland, die "wreedaardige" kommando's afgeskaf ${ }^{18}$. Sonder voldoende troepe op die grens was die grensboere weerloos teen die swartes.

Blankes aan die grens kon nou nie meer eie beskermingsmaatreëls toepas nie, maar moes wag vir toestemming van die regering, wat honderde kilometers van die grens af was en nie begrip vir hulle omstandighede gehad het nie. Boonop was daar nie 'n sterk en blywende staandemag om in hulle behoeftes te voorsien nie.

Ongeveer 20000 Xhosas het die grens oorgesteek en binne 'n paar weke 15 jaar se harde werk verwoes. Vierhonderd ses en vyftig plaashuise is afgebrand, 300 geplunder, 60 waens verwoes, 5700 perde, 115000 beeste en 162 000 skape en bokke is gesteel. Baie boere is vermoor hoewel dit soms gebeur het dat die Xhosas die vroue en kinders se lewens gespaar het $^{19}$.

Tydens hierdie invalle het sommige Setlaars skuiling in die klein dorpies in die Oos-Kaap gaan soek, omdat dit makliker verdedigbaar was as wat hulle afgeleë plase was. Onder leiding van D'Urban het die burgerkommando's en soldate teenaanvalle geloods en die oorlog beëindig. Nadat die vyand teruggedryf is oor die grense het die boere na hulle plase teruggekeer. Huise moes weer van vooraf gebou word. Mettertyd is die huise dan ook so gebou om hierdie aanvalle af te weer. Dit het tot gevolg gehad dat die onderste vloer geen vensters gehad het nie en dat 'n paar meter hoë muur om elke huis gebou is - 'n somber huis vir lewenslustige kinders.

Dit het egter ' $n$ moedige, geharde en selfversorgende nasie tot gevolg gehad.

\section{Slot}

Dr Philip was steeds besig met sy bedrywighede. Hy het aangedring op die hersiening van die grensstelsel en het luid verkondig dat die behandeling wat die Bantoe ontvang het ' $n$ klad op Brittanje se naam was. 'n Nuwe beleid is geëis, wat op vriendelikheid ipv dwang gegrond moes wees, omdat dit mensliker, goedkoper en voordeliger sou wees.

Die finansiële faktor, dws die Britse besuinigingsbeleid het meegebring dat die owerheid 
nie bereid was om die grensbewoners te verdedig nie. Terselfdertyd het die filantropiese faktor die koloniste verhinder om hulleself te verdedig. Die omverwerping van die grensbeleid was nou vir baie ' $n$ beslissende faktor. Hulle sou die Britse gesag afwerp deur 'n vreedsame rebellie, die Groot Trek.

*Lt A.M. le Roux, Honns Joernalistiek en Skakelkunde is verbonde aan die Militêre Informasieburo van die SAW.

\section{Verwysings}

1. Pelzer, A.N. (Dr), Jan van Riebeeck 1618-1677, Unie-Boekhandel (Edms) Bpk, Pretoria, 1944. p 24

2. Boëseken, A.F. Avontuur in die Vreemde, Tafelberg Uitgewers, 1971, p 41.
3. Muller, C.F.J. (onder redaksie van), Vythonderd Jaar Suid-Afrikaanse Geskiedenis, Academica, Pretoria en Kaapstad, 1975. p 30.

4. Pelzer, p 33.

5. Nuwe Afrikaanse Kinderensiklopedie, no 9, NASOU, Goodwood, 1982. p 283.

6. Child, D. Yesterday's Children, Howard Timmins, Cape Town 1969. p 41.

7. Ibid, $p 45$.

8. Ibid, $p 50$.

9. Zietsman, P.L. Die Verdediging van en die Verdedigingsbeleid aan die Oosgrens, 1941, p 8.

10. Green, M.S. Suid-Afrika in wording, Maskew Miller Bpk, Kaapstad, 1960. p 37.

11. Zietsman, $\mathrm{p} 46$

12. Ibid, $p 54$.

13. Ibid, 054 .

14. Van Jaarsveld, F.A. Van Van Riebeeck tot P.W., Perskor, Doornfontein, Johannesburg, 1969. p 107

15. Kinderensiklopedie no 8. p 269

16. Child, p 85.

17. Van Jaarsveld, $p 103$.

18. Muller, $p 147$

19. Ibid, p 147. 